\title{
In-situ polymerization of PMMA inside decellularized dermis using UV photopolymerization
}

Kwangwoo Nam, ${ }^{\mathrm{a}, \mathrm{b}}$, Yukiko Shimatsu ${ }^{\mathrm{a}}$, Rie Matsushima ${ }^{\mathrm{a}}$, Tsuyoshi Kimura ${ }^{\mathrm{a}, \mathrm{b}}$, Akio Kishida, ${ }^{\mathrm{a}, \mathrm{b}, *}$

${ }^{a}$ Institute of Biomaterials and Bioengineering, Tokyo Medical and Dental University, 2-3-10 Kanda-Surugadai, Chiyoda-ku, Tokyo 101-0062, Japan

b Japan Science and Technology Agency, CREST, 5, Sanbancho, Chiyoda-ku, Tokyo 102-0075, Japan

TEL: 03-5841-8028

FAX: 03-5841-8028

E-mail: Kishida.mbme @tmd.ac.jp 
ABSTRACT

Polymerization is a technique used to functionalize soft tissues and to produce interface tissues. Here, we developed a method for functionalizing soft tissue with diverse polymers, using in-situ polymerization of monomers that were absorbed into the tissue. Specifically, methyl methacrylate (MMA) and a photoinitiator (Irgacure® ${ }^{\circledR} 184$ ) were applied to the decellularized dermis, which was polymerized in-situ using irradiating ultraviolet light. MMA polymerization in-situ was possible because the monomers filled the cavities of the decellularized dermis. It took approximately $40 \mathrm{~min}$ to complete polymerization, but we found that the rate and depth of polymerization could be adjusted by using mixtures of Irgacure ${ }^{\circledR} 184$ and Irgacure ${ }^{\circledR}$ 819. The addition of Irgacure ${ }^{\circledR} 819$ increased polymerization, indicating that polymerization of MMA had occurred inside the dermis. Additionally, we showed that a complex of dermis and poly(methyl methacrylate) (PMMA) increase mechanical strength, which indicates that the PMMA is anchored to collagen fibers. This makes the complex very stable, giving it the functionality of both soft and hard tissue.

Keywords: decellularization; dermis; poly(methyl methacrylate); complex; photopolymerization 


\section{Introduction}

An interface tissue, such as an anterior cruciate ligament that connects femur and tibia or a scaffold for enabling regeneration of bone-cartilage, should be biologically compatible with both soft and hard tissue [1-3]. Designs for new soft-to-hard tissue interfaces have focused on using decellularized tissue-polymer complexes, in which decellularized tissue and poly(methyl methacrylate) (PMMA), which possesses mechanical toughness and shows fast remodeling in the implanted area without causing any fibrous encapsulation, are used as the base materials. Allowing the decellularized tissue to absorb a polymer solution and then interlinking the polymers would be the most convenient method for producing a complex, but this task is made difficult because of the insufficient absorption of hydrophobic solvents, which are required to dissolve the polymer [4]. Where polymers are hydrophilic, water can be used as solvent; however, such polymers possess only hydroxyl or carboxyl groups, and these are miscible with collagen [5-7].

Therefore, saturating the decellularized tissue with monomers before polymerization is a more promising method. Here, the monomers fill the cavities that are created when the cells are removed, and they can be polymerized and anchored to collagen bundles in the tissue in-situ. The method would produce an intermediate phase 
that does not have an interface between the polymer and the tissue. When placing a complex such as this between soft and hard tissue, the section without the polymer would maintain the properties of native tissue, allowing cells to infiltrate and integrating with the tissue, while the section inside the dermis containing the polymer would "cement" to hard tissue. Therefore, a complex of synthetic material and native tissue could be produced that would be compatible with both soft and hard to tissues. These methods could have practical applications, for example, in preparation of percutaneous devices, where integration between the artificial catheter and soft tissue is required to prevent the downgrowth of the epidermis [8]. Previously, we showed that monomer absorption and in-situ polymerization can occur using benzyl peroxide (BPO) and $N, N^{\prime}$-dimethyl-p-toluidine (DMPT) as initiators, and this method is often used for cementing bones, demonstrating that partial polymer-tissue in-situ polymerization is possible $[4,9]$.

In this study, we aimed to expand on the monomers currently used for interface tissue by establishing a new method of in-situ polymerization incorporating UV photopolymerization. Photopolymerization has various biomedical applications because of its powerful spatial control of reaction kinetics, minimal heat production, and ability to rapidly convert a monomer to a cross-linked network under physiologic conditions 
[10-12]. Furthermore, UV irradiation is a widely used technique for polymerizing methyl methacrylate (MMA) because it is fast, simple, and requires no other chemicals than the monomer and photoinitiator [13-15]. The wavelength that penetrates into the dermis, $354 \mathrm{~nm}$, is found in the UVA range $(320-400 \mathrm{~nm})$ [16]. UV damage to cellular DNA can cause cancer or increase matrix metalloprotease (MMP) activity, but UV irradiation of decellularized tissue, in which no cells exist, should cause no such problems [17-19]. Furthermore, UV photopolymerization is often used in the cellular encapsulation technology [3-5]. As a model study, here, we report on the preparation and characterization of a decellularized tissue-polymer complex, made from dermis and methyl methacrylate (MMA) and created via in-situ polymerization, and we investigate its potential as a complex material for the tissue interface.

\section{Experimental section}

\subsection{Materials}

Fresh porcine skin was obtained from a local slaughterhouse (Tokyo Shibaura Zouki, Tokyo, Japan). The epidermal tissue and fat were trimmed, and the dermis was washed in phosphate-buffered saline (PBS) (Invitrogen, Japan). After purchase, MMA 
(Wako Pure Chemicals, Japan) was distilled under reduced pressure to remove inhibitors. Both 1-hydroxy-cyclohexyl-phenyl-ketone (Irgacure®184, Ciba-Geigy, Switzerland) and bis(2,4,6-trimethylbenzoyl)-phenylphosphineoxide (Irgacure ${ }^{\circledR} 819$, Ciba-Geigy, Switzerland) were used as photoinitiators. DNase I (Roche, Germany) and magnesium chloride solutions (Wako Pure Chemicals, Japan) were purchased and used in their original states, as described below.

\subsection{Preparation of the decellularized dermis}

The decellularized dermis was prepared under high-pressure using the methods described in our previous studies [4,9,20-21]. In short, in order to dismantle dermis cells, the specimens were sealed inside polyethylene bags containing PBS, and hydrostatically pressurized using a cold isotactic pressurization machine (Dr. CHEF, Kobe Steel, Ltd., Hyogo, Japan) at $980 \mathrm{Mpa}, 30^{\circ} \mathrm{C}$, and for $10 \mathrm{~min}$. Subsequently, specimens were washed (by a process of continuous gentle shaking) in saline containing $0.2 \mathrm{mg} / \mathrm{mL}$ DNase I and $50 \mathrm{mM}$ magnesium chloride for 10 days at $37^{\circ} \mathrm{C}$, treated with $80 \%$ ethanol in saline for 3 days at $4{ }^{\circ} \mathrm{C}$, and finally treated with a citric acid buffer for 3 days at $37^{\circ} \mathrm{C}$. Prepared samples were stored in PBS at $4^{\circ} \mathrm{C}$. 


\subsection{Characterization of the decellularized dermis}

Following decellularization, in order to observe structures and remaining cells, specimens were fixed in $10 \%$ neutral buffered formalin, embedded in paraffin, and cut into sections $4 \mu \mathrm{m}$ thick. These sections were stained with Mayer's hematoxylin-eosin (H-E) and (EVG) stains, and imaged using microscopy (Coolscope, Nikon Co., Ltd., Tokyo, Japan). To enable quantification of residual cells in the tissue, native and decellularized dermis samples were freeze-dried and suspended for $12 \mathrm{~h}$ at $55^{\circ} \mathrm{C}$ in 0.5 $\mathrm{mL}$ of a lysis buffer containing $50 \mu \mathrm{g} / \mathrm{mL}$ protease $\mathrm{K}, 50 \mathrm{mM}$ Tris- $\mathrm{HCl}, 1 \%$ (w/v) SDS, $100 \mathrm{mM} \mathrm{NaCl}$, and $20 \mathrm{mM}$ EDTA-2Na. DNA was extracted with phenol-chloroform and purified by ethanol precipitation. Using a UV/visible-light spectrophotometer (V-560, JASCO, Tokyo, Japan), we measured the content of residual DNA at $260 \mathrm{~nm}$.

\subsection{UV photopolymerization of MMA}

MMA and Irgacure ${ }^{\circledR} 184$ were deoxygenated using argon and transferred into a glove box workstation (M. Braun Inertgas-Systeme $\mathrm{GmbH}$, Germany) where $\mathrm{O}_{2}$ and $\mathrm{H}_{2} \mathrm{O}$ concentrations were $<0.1 \mathrm{ppm}$. Reaction mixtures of MMA and Irgacure ${ }^{\circledR} 184$ were sealed inside polyethylene bags, with molar ratios set as shown in Table 1 . They were photopolymerized under a UV lamp (wavelength $=365 \mathrm{~nm}$; light intensity $=8.26$ 
$\mathrm{mW} / \mathrm{cm}^{2}$ ) for $80 \mathrm{~min}$ at $25^{\circ} \mathrm{C}$ to produce single-type-Irgacure $®$ PMMA ( $s$ PMMA). The temperature during the polymerization was measured every 5 minutes by thermography (using a MobIR ${ }^{\circledR}$ M8 thermal camera, China). We used the same photopolymerization conditions to produce dual-type-Irgacure ${ }^{\circledR}$ PMMA ( $d$ PMMA) from a mixture of Irgacure ${ }^{\circledR} 184$ and $\operatorname{Irgacure}{ }^{\circledR} 819$ (molar ratio $=1: 1$ ). Following polymerization, we obtained PMMA by dissolving and precipitating the polymer in methanol and acetone, respectively. To determine the molecular weight and polydispersity of the PMMA, we carried out gel permeation chromatography (GPC) analysis at $40^{\circ} \mathrm{C}$ on a Shodex GPC-101 high-speed liquid chromatography system, which was equipped with a guard column (Shodex GPC LF-G), two $30 \mathrm{~cm}$ mixed columns (Shodex GPC LF-804, exclusion limit $=2 \times 10^{6}$ ), and a differential refractometer (Shodex RI-71S). $N, N$-dimethylformamide (DMF) containing $10 \mathrm{mM} \mathrm{LiBr}$ was used as an eluent with a flow rate of $0.8 \mathrm{~mL} / \mathrm{min}$. The GPC system was calibrated using PMMA standards (Shodex, STANDARD M-75, $M \mathrm{p}=2.89 \times 10^{3}-9.65 \times 10^{5}$ ).

\subsection{Preparation of decellularized dermis/polymer complex}

Decellularized dermis was freeze-dried under reduced pressure overnight, heat-sealed inside a polyethylene bag containing MMA and the photoinitiator, and 
MMA was photopolymerized at $25^{\circ} \mathrm{C}$ for 80 min using a UV lamp (wavelength $=365$

$\mathrm{nm}$, light intensity $=8.26 \mathrm{~mW} / \mathrm{cm}^{2}$ ). Following polymerization, specimens were removed from their bags and immersed in chloroform for 1 day. The complex was then placed in methanol to remove the monomer from the matrix and rinsed with PBS. To measure the molecular weight and polydispersity of the polymer in the dermis, the complex was first immersed in acetone for 1 day before the solution was poured into methanol for re-precipitation; PMMA was then detected and measured using the same GPC analysis procedure described above. We also made a similar polymer-tissue complex using 2-hydroxyethyl methacrylae (HEMA) (Kanto Chemical, Tokyo, Japan) by absorbing the monomer and polymerizing it at $254 \mathrm{~nm}$ and $365 \mathrm{~nm}$ to compare the photopolymerization behavior with MMA.

\subsection{Characterization of the decellularized dermis/polymer complex}

Samples were allowed to swell in water at room temperature for $24 \mathrm{~h}$ in order to determine the water content of the complex. Water content percentages were calculated using the following equation:

$$
\text { Water content }(\%)=\frac{W_{h}-W_{d}}{W_{h}} \times 100
$$

where $W_{\mathrm{h}}$ is the hydrated weight, and $W_{\mathrm{d}}$ the dried weight, of a sample. 
A razor blade was used to make a small dent on the surface of the samples, before they were fractured and freeze-dried overnight. The fracture surface of the complex was sputter-coated with gold and observed using a scanning electron microscope (SEM) (S-3400N, Hitachi High-Technologies Co., Tokyo, Japan).

Compression properties of the complex were measured using a creep meter (Yamaden Co., Ltd., Tokyo, Japan), with samples first immersed in water at room temperature for $24 \mathrm{~h}$ before their compression at $0.05 \mathrm{~mm} / \mathrm{min}$ and $20 \mathrm{~N}$. Measurements were converted into stress-strain curves.

\section{Results}

\subsection{Decellularization of dermis}

Dermis samples, before and after decellularization, are shown in Figure 1. Cells were not visible after decellularization (Figure 1D). The decellularization process did not disturb or damage the structure of the extracellular matrix (ECM); collagen and elastin fibers were maintained, and no trace of debris was left behind. This is consistent with our previous findings, which showed that, given the right circumstances, ECM structures are not disrupted [4,20-23]. Furthermore, we found that the high pressure did 
not affect the structure of collagen bundles and elastin fibers (Figure 1E and 1F). The residual DNA content after decellularization was very low, which showed that the cellular components in the dermis had been washed effectively (data not shown) [4].

\subsection{In-situ photopolymerization of PMMA}

The characteristics of the bulk sPMMAs and $d$ PMMAs, obtained by UV polymerization, are listed in Table 2 . The values of $T_{\max }$, which denotes the maximum temperature reached during polymerization, and $t_{\max }$, which indicates the time at which $T_{\max }$ occurred, show that polymerization using only Irgacure ${ }^{\circledR} 184$ took at least 35 minutes (Supplementary Figure 1). Conversion percentage varied according to the concentration of Irgacure ${ }^{\circledR} 184$, ranging from $64 \%-88 \%$. Molecular weights $\left(\bar{M}_{\mathrm{n}}\right)$ of specimens were between $5 \times 10^{4}$ and $7 \times 10^{4}$. Polymerizations in which higher concentrations of Irgacure ${ }^{\circledR} 184$ were used resulted in lower molecular weights and higher conversion percentages, but required more time. However, the addition of Irgacure ${ }^{\circledR} 819$ to Irgacure ${ }^{\circledR} 184$ resulted in a faster curing time [14] of approximately 30 min. The maximum UV absorption wavelength of Irgacure ${ }^{\circledR} 819$ was approximately $354 \mathrm{~nm}$ (Supplementary Figure 2), and this improved level of UV absorption may have initiated polymerization more quickly. However, the addition of Irgacure ${ }^{\circledR} 819$ to 
Irgacure ${ }^{\circledR} 184$ did not significantly change the observed molecular weight or conversion percentage.

\subsection{Decellularized dermis/polymer complex}

The shape of the decellularized dermis/polymer complex was no different from that of the decellularized dermis. We could not detect any leaking of unreacted polymer in either water or PBS, indicating that the methanol rinsing process was successful. The molecular weights and the conversion percentages of $s$ PMMA200 and dPMMA200, obtained from the decellularized dermis/polymer complexes, are listed in Table 3. The molecular weight of PMMA in the complex was $\overline{M_{\mathrm{n}}}=7 \times 10^{4}$, with a conversion of approximately 55\% for $s$ PMMA200 and 83\% for $d$ PMMA200. Comparing conversion percentages for sPMMA200 in Tables 2 and 3, it is clear that the conversion percentage was lower in the sPMMA200 complex. Comparing the conversion rate and the molecular weight of PMMA in the decellularized dermis/sPMMA200 and decellularized dermis/dPMMA200, conversion rates were substantively higher for decellularized dermis/dPMMA200, but molecular weights were similar. Where we used Irgacure ${ }^{\circledR} 819$, there was no significant change in molecular weight, but conversion percentage was increased. 
Figures 2a, 2c, and 2e show images of the central portions of decellularized dermis and decellularized dermis/polymer complexes. No change in size or shape was evident after the complexes were created. Their surfaces were hard, but not as hard as the bulk PMMA. The fracture surfaces shown in Figures $2 \mathrm{~b}, 2 \mathrm{~d}$, and $2 \mathrm{f}$ show that the layered ECM structure had disappeared by the time complexation was complete. We did not find pores that would indicate monomer or polymer leakage. Therefore, we suggest that these complexes are not simple polymer-coated dermis. The collagen bundle region, filled with internally anchored collagen, is shown as a schematic image in Figure 3. First, this collagen region is filled MMA and Irgacure ${ }^{\circledR}$, and then polymerization by UV hardens the matrix. When the pores are filled with PMMA, it resembles a monolithic structure. The collagen bundle changes its shape after the polymerization, developing a more aggregated bundle shape.

The water content of the complexes was found to be lower than that of the decellularized dermis (Figure 4). Absorption of water stabilized after $60 \mathrm{~min}$, and, using Irgacure ${ }^{\circledR} 184$, the water content of the decellularized dermis/polymer complex was $<40 \%$. Using Irgacure ${ }^{\circledR} 819$, the water content decreased to $<30 \%$. This result indicates that the polymerization that took place when both photoinitiators were used occurred not only in the outer part of the complex, but also in the central part, and implies that 
the polymer in the decellularized dermis is stable in water.

The results of the compression test are shown in Figure 5. The decellularized dermis/polymer complex was much stiffer than the native dermis and the decellularized dermis. Whereas the maximum compression strain for the complex was $10 \%$, it was $40 \%$ for the native dermis. We also observed the characteristics of the initial phase of lightly stressed native tissue. In the case of bulk polymers, the stress-strain curve was linear. However, for the complexes, we found a slight non-linear increase in the initial stages of the curve, indicative of this initial phase (Figure $5 b$ and $5 c$ ).

\section{Discussion}

In this study, we decellularized dermis using high hydrostatic pressurization in order to eliminate cells while maintaining tissue structure. We filled the void created by cell elimination with monomers, and used polymerization to produce a firm and strong polymer anchored to the ECM. We found that our method of using high hydrostatic pressure and thorough rinsing to destroy and eliminate cells, respectively, was effective. Components other than collagen and elastin should also ideally be eliminated in order to suppress the pro-inflammatory host response, and we found that the level of residual 
content was sufficiently low when using our method, similar to our previous results [4,20-23]. Furthermore, collagen and elastin fibers remained undamaged, demonstrating that the high pressure did not affect their structures [21].

We found that polymerization of the MMA occurred within 40 minutes of UV irradiation. There was no difficulty with monomer infiltration, which was expected because we previously reported that it would occur under similar conditions [4]. The monomers infiltrate the soft tissue by capillary action and polymerize inside the cavities, anchoring firmly to the ECM. In previous studies, the Nakabayashi research group promoted infiltration by using amphiphilic monomers [24,25]. The rate of polymerization obtained using a photoinitiator is known to depend on UV intensity and wavelength. Irgacure ${ }^{\circledR} 184$ and Irgacure ${ }^{\circledR} 819$ are stimulated by $365 \mathrm{~nm}$ UV [26], but we found that the maximum absorption wavelength was slightly lower for the Irgacure ${ }^{\circledR}$ 184, implying that its polymerization rate would be low and curing would take longer. Therefore, we added Irgacure ${ }^{\circledR} 819$ in order to produce faster polymerization because its highest absorption occurs at $365 \mathrm{~nm}$. However, we noted that using Irgacure ${ }^{\circledR} 819$ alone did not increase the rate of polymerization because it is generally used for thorough polymerization [27]; for example, Irgacure ${ }^{\circledR} 184$ is used for surface polymerization, while Irgacure ${ }^{\circledR} 819$ is used for interior polymerization. The 
conversion percentages of two photoinitiators were similar because the values were measured after the heat of polymerization was detected. In summary, using Irgacure ${ }^{\circledR}$ 184 alone induced slow surface polymerization, while using a mixture of Irgacure ${ }^{\circledR} 184$ and Irgacure ${ }^{\circledR} 819$ resulted in faster surface and interior polymerization.

What was the effect of UV irradiation on the components of the decellularized dermis? UV can damage cellular DNA causing cancer or increasing matrix metalloprotease (MMP) activity [10-12]. However, such issues would be unlikely to occur with our method because the residual amount of DNA is very low. The main problem potentially posed by UV irradiation, would be the effect on the ECM, especially to collagen. It is possible that UVA-induced cross-linking of collagen occurs only in the presence of a photosensitizing agent that can release free radicals or reactive oxygen species to cause the formation of hydrogen bonds or cross-links between the amino acids in collagen chains [28]. Therefore, collagen cross-linking could be due to the existence of photoinitiators within the cavities of decellularized tissues. This also implies that polymerization and cross-linking may occur simultaneously, forming stable polymer-collagen complexes. Thus, the retention of polymer inside the ECM could contribute to stable chemical reactions.

It currently unclear whether the collagen within the ECM was denatured by UV 
irradiation $[29,30]$, but we found no evidence to suggest that the collagen had been denatured during in-situ polymerization. Denaturation of collagen leads to the breakdown of the fibrillar microstructure in the collagen bundle region. However, we found that the structures of the collagen bundle region were unchanged after polymerization, implying that full collagen denaturation had not occurred.

We found that the polymerization inside the decellularized tissue was no different from that of bulk polymerization because the conversion rate and molecular weight of PMMA in the complex were almost identical to those of the bulk PMMA. This implies that polymerization occurred within the tissue without any difficulties. We observed no leaking of unreacted monomer, indicating that the toxicity caused by such a leak could be avoided using out methods. Keeping the Irgacure ${ }^{\circledR}$ concentration low and rinsing the unreacted monomer to avoid cell toxicity is very important [31,32]. Since we used a small amount of photoinitiator and we eliminated the monomer inside the complex, cell toxicity was unlikely to be a problem. Furthermore, in our previous work we reported no sign of inflammatory response [4,9]. Therefore, we believe that this complex is safe to use as a base material for tissue interface.

In the case of the decellularized dermis/dPMMA200 complex, the high conversion we observed indicated that the polymerization inside the dermis had occurred in a 
similar way to the bulk polymerization. It is thought that the monomers filled the cavities within the dermis and polymerized. A layered structure could not be seen after polymerization, indicating that the tissue-polymer complex had indeed formed. We noted that it is possible to obtain the same polymer-tissue complex using poly(2-hydroxy methacrylic acid) (PHEMA). HEMA was absorbed and polymerized in the tissue more easily, with a faster polymerization rate (Supplementary Figure 3). Our results suggest that even hydrophobic monomers can infiltrate the native tissue and polymerize within the matrix, although the polymerization is much slower. Collagen damage may have occurred because high heat can cause denaturation (maximum temperature, $78.2^{\circ} \mathrm{C}$ ) [33]. However, we suggest that full collagen denaturation did not occur because we did not observe any shrinkage during the process. Furthermore, for collagen to be denatured, its molecules should be in a mobile environment, where the disentangled collagen amino chains dissolute and become random coils. In our study, heat would be produced by polymerization, but mobility would be substantially decreased by solidification. There is the possibility that partial denaturation of collagen molecules could occur at temperatures above $37^{\circ} \mathrm{C}$ [34], but the decrease in the mobility would eventually suppress this effect.

Based on the results of our compression test, we speculate that our method resulted 
in the stable existence of the PMMA in the dermis. This was indicated by a small, but clear, increase in stress at the early stage of strain for both the decellularized dermis/sPMMA complex and the decellularized dermis/dPMMA complex. Therefore, it is clear that the addition of the polymer into the dermis made the tissue much stiffer. Furthermore, using Irgacure ${ }^{\circledR} 184$ and Irgacure ${ }^{\circledR} 819$ together made the dermis complex even stiffer, indicating that using two curing agents would be most efficient when forming complexes. As we previously stated, UVA-induced cross-linking of collagen and polymerization could cause increased rigidity in the complex. For decellularized dermis/sPMMA complexes, a site exist at which polymerization did not occur, while homogeneous distribution of polymers inside the dermis occurred in decellularized dermis/dPMMA complexes.

\section{Conclusion}

We found that it is possible to combine a decellularization technique with bulk polymerization to produce a complex consisting of decellularized tissue and a synthetic polymer. The monomers that filled the cavities left behind when cells were removed became a polymer after 40 min of UV irradiation. We showed that the polymer was 
anchored to collagen fibers and could exist stably within the tissue. To our knowledge, our study is the first to report the creation of a hydrophobic polymer and soft tissue complex that could function as a soft-to-hard tissue interface. We firmly believe that the study contributes to advances in interface tissue engineering. In future research, it will be necessary to further investigate several factors of the study, including the denaturation of collagen by UV irradiation, the anchoring effect, and the monomer penetration rate. We are pursuing this research in order to obtain a deeper understanding of in-situ polymerization of soft tissues using diverse monomers.

\section{Acknowledgements}

This work was supported by a Grant-in-Aid from the Core Research for

Evolutional Science and Technology (CREST) of the Japan Science and Technology Agency (JST).

\section{References}

[1] Seidi A, Ramalingam M, Elloumi-Hannachi I, Ostrovidov S, Khademhosseini A. Gradient biomaterials for soft-to-hard interface tissue engineering. Acta Biomater 
2011; 7: 1441-51.

[2] Spalazzi JP, Gallina J, Fung-Kee-Fung SD, Konofagou EE, Lu HH. Elastographic imaging of strain distribution in the anterior cruciate ligament and at the ligament-bone insertions. J Orthop Res 2006; 24: 2001-2010.

[3] Erisken C, Kalyon DM, Wang H. Functionally graded electrospun polycaprolactone and beta-tricalcium phosphate nanocomposites for tissue engineering applications.

Biomaterials 2008; 29: 4065-4073.

[4] Matsushima R, Nam K, Shimatsu Y, Kimura T, Fujisato T, Kishida A. Decellularized dermis-polymer complex provides a platform for soft-to-hard tissue interfaces. Mat Sci Eng C 2014;35:354-62.

[5] Nezu T, Winnink FM. Interaction of water-soluble collagen with poly(acrylic acid) Biomaterials 2000;21:415-9.

[6] Svintradze D V, Mrevlishvili GM, Metreveli N, Jariashvili K, Namicheishvili L, Skopinska J, Sionkowska A. Collagen-DNA Complex Biomacromolecules 20089 (1), 21-28

[7] Sionkowska A.The influence of UV light on collagen/poly(ethylene glycol) blends. Polym Degrad Stab 2006; 91 : 305-312 
[8] Gangjee T, Colaizzo R, von Recum A F. Species-related differences in percutaneous wound healing. Ann Biomed Eng 1985; 13: 451-67.

[9] Nam K, Matsushima R, Shimatsu Y, Kimura T, Fujisato T, Kishida A. In vivo characterization of a decellularized dermis-polymer complex for use in percutaneous devices. Artif. Organs In print. (doi:10.1111/aor.12330)

[10]Williams CG, Malik AN, Kim TK, Manson PN, Elisseeff JH. Variable cytocompatiblity of six cell lines with photoinitiators used for polymerizing hydrogels and cell encapsulation. Biomaterials 2005;26:1211-8.

[11]Bryant SJ, Nuttelman CR, Anseth KS. Cytocompatiblity of UV and visible light photoinitiating systems on cultured NIH/3T3 fibroblasts in vitro. J Biomater Sci Polym Ed 2000;11:439-57.

[12]Fairbanks BD, Schwartz MP, Bowman CN, Anseth KS. Photoinitiated polymerization of $\quad$ PEG-diacrylate with lithium phenyl-2,4,6-trimethylbenzoylphospphinate: polymerization rate and cytocompatiblity. Biomaterials 2009;30: 6702-7.

[13]Ishihara M, Nakanishi K, Ono K, Sato M, Kikuchi M, Saito Y, Yura H, Matsui T, Hattori H, Uenoyama M, Kurita A. Photocrosslinkable chitosan as a dressing for wound occlusion and accelerator in healing process. Biomaterials 2002;23: 833-40. 
[14]Nguyen KT, West JL. Photopolymerizable hydrogels for tissue engineering applications. Biomaterials 2002; 23: 4307-14.

[15]Lovell LG, Lu H, Elliott JE, Stansbury JW, Bowman CN. The effect of cure rate on the mechanical properties of dental resins. Dent Mater 2001; 17: 504-11.

[16]Fisher GJ, Kang S, Varani J, Bata-Csorgo Z, Wan Y, Datta S, Voorhees JJ. Mechanisms of Photoaging and Chronological Skin. Aging Arch Dermatol 2002; 138: $1462-70$.

[17]Cleaver JE Crowley E. UV damage, DNA repair and skin carcinogenesis. Front Biosci 2002; 7:1024-43.

[18]Dong KK, Damaghi N, Picart SD, Markova NG, Obayashi K, Okano Y, Masaki H, Grether-Beck S, Krutmann J, Smiles KA, Yarosh DB. UV-induced DNA damage initiates release of MMP-1 in human skin. Exp Derma 2008; 17: 1037-44.

[19] Sternlicht MD Werb Z. How matrix metalloproteinases regulate cell behavior. Ann Rev Cell Dev Biol 2001; 17: 463-516.

[20]Funamoto S, Nam K, Kimura T, Murakoshi A, Hashimoto Y, Niwaya K, Kitamura S, Fujisato T, Kishida A. The use of high-hydrostatic pressure treatment to decellularize blood vessels. Biomaterials 2010; 31: 3590-5.

[21]Negishi J, Funamoto S, Kimura T, Nam K, Higami T, Kishida A. Effect of 
treatment temperature on collagen structures of the decellularized carotid artery using high hydrostatic pressure. J Artif Organs, 2011; 14: 223-31.

[22] Hashimoto Y, Funamoto S, Sasaki S, Honda T, Hattori S, Nam K, Kimura T, Mochizuki M, Fujisato T, Kobayashi H, Kishida A. Preparation and characterization of decellularized cornea using high-hydrostatic pressurization for corneal tissue engineering. Biomaterials 2010;31 3941-8.

[23] Hashimoto Y, Funamoto S, Kimura T, Nam K, Fujisato T, Kishida A. The effect of decellularized bone/bone marrow produced by high-hydrostatic pressurization on the osteogenic differentiation of mesenchymal stem cells. Biomaterials 2011; 32: 7060-7.

[24]Nakabayashi N, Kojima K, Masuhara E. The promotion of adhesion by the infiltration of monomers into tooth substrates. J Biomed Mater Res, 1982; 16: 265-73.

[25]Suzuki S, Nakabayashi N, Masuhara E. The evaluation of new dental resins prepared with polyfunctional methacrylate monomers. J Biomed Mater Res $1982 ; 16: 275-87$.

[26]Schafer KJ, Hales JM, Balu M, Belfield KD, Van Stryland EW, Haganb DJ. Two-photon absorption cross-sections of common photoinitiators. J Photochem 
Photobiol Chem 2004; 162A: 497-502.

[27]Moona JH, Shula YG, Han HS, Hong SY, Choi YS, Kim HT. A study on UV-curable adhesives for optical pick-up: I. Photo-initiator effects. Int J Adhes Adhesives 2005; 25: 301-12.

[28]Dahl BJ, Spotts E, Truong JQ Corneal collagen cross-linking: An introduction and literature review. Optometry 2012; 83: 33-42.

[29] Metreveli NO, Jariashvili KK, Namicheishvili LO, Svintradze DV, Chikvaidze EN, Sionkowska A, Skopinska J. UV-vis and FT-IR spectra of ultraviolet irradiated collagen in the presence of antioxidant ascorbic acid Ecotoxicol Environ Saf 2010; 73: $448-455$

[30]Jariashvili KK, Madhan B, Brodsky B, Kuchava A, Namicheishvili L, Metreveli N. UV Damage of Collagen: Insights from Model Collagen Peptides. Biopolymers 2012; 97: 189-198.

[31]Leggat PA, Kedjarune U.Toxicity of methyl methacrylate in dentistry. Int Dent J 2003; 53:126-31.

[32] Ovsianikov A, Malinauskas M, Schlie S, Chichkov B, Gittard S, Narayan R, Löbler M, Sternberg K, Schmitz KP, Haverich A. Three-dimensional laser micro- and nano-structuring of acrylated poly(ethylene glycol) materials and evaluation of their 
cytoxicity for tissue engineering applications. Acta Biomater 2010; 7: 967-974.

[33]Gevorkian SG, Allahverdyan AE, Gevorgyan DS, Simonian AL, Hu C-K. Stabilization and anomalous hydration of collagen fibril under heating. PLoS ONE 2013; 8: e78526.

[34]Leikina E, Mertts MV, Kuznetsova N, Leikin S. Type I collagen is thermally unstable at body temperature. Proc Natl Acad Sci USA 2002; 99: 1314-1318. 
Figure legends

Figure 1. Photographs (A,B), H\&E-stained sections (C,D) and EVG-stained sections (E,F) of native dermis $(\mathrm{A}, \mathrm{C}, \mathrm{E})$ and decellularized dermis after thorough washing $(\mathrm{B}, \mathrm{D}, \mathrm{F})$.

Figure 2. Photographic images and SEM images of decellularized dermis $(a, b)$, a decellularized dermis/sPMMA complex (c,d), and a decellularized dermis/dPMMA complex (e,f).

Figure 3. (A) Schematic image of collagen bundle inside the dermis, (B) H\&E-stained section of the dermis and (C) SEM image of the dermis. (D) Schematic image of collagen bundle and polymer inside the complex, (E) H\&E-stained section of the complex and (F) SEM image of the complex. The arrow indicates the hardened collagen bundle and the dotted line implies the collagen bundle region.

Figure 4. Water contents of decellularized dermis/PMMA complexes after 24-h water absorption.

Figure 5. (A) Stress-strain curve of the Native dermis (-.-.-), decellularization dermis

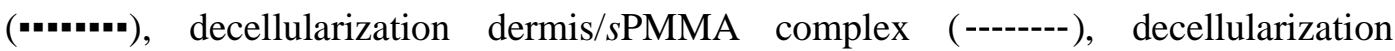
dermis/dPMMA complex (— $)$, bulk $s$ PMMA $(---\cdot)$, and bulk $d$ PMMA (………..). The enlarged part of stress-strain curve shown in the rectangle is shown in B and C. 
Figure 6. Schematic images of preparation of decellularized dermis/polymer complex structure. A (upper): Decellaulrized dermis/sPMMA200 complex and B (below): Decellularized dermis/dPMMA200 complex. The white part in the decellaulrized dermis/sPMMA200 complex is where the monomer and the Irgacure®184 had been rinsed because the polymerization did not occur. 
Table 1 Compositions of reaction mixtures used to make six types of PMMA.

\begin{tabular}{cccc}
\hline \multirow{2}{*}{ Photo-initiator } & \multicolumn{3}{c}{ MMA:photo-initiator (mole ratio) } \\
\cline { 2 - 4 } & $s$ MMA200 & $s$ MMA40 & $s$ MMA20 \\
\hline Irgacure $\AA$ 184 & & & \\
Irgacure $\AA$ 18 184 & $d$ MMA200 & $d$ MMA40 & $d$ MMA20 \\
+ Irgacure $\AA 819$ & & & \\
\hline
\end{tabular}


Table 2 Conversion and molecular weight of PMMA obtained by UV curing

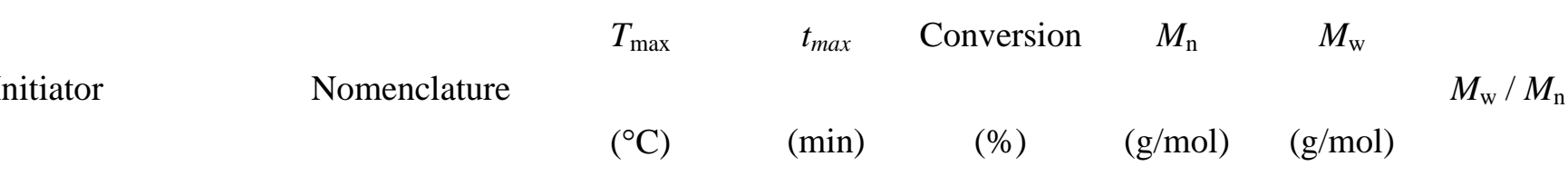

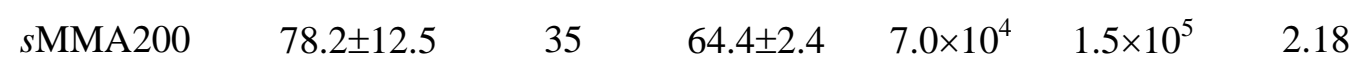

Irgacure ${ }^{\circledR} 184$

\begin{tabular}{lrcrrrr}
$s$ MMA40 & $73.9 \pm 2.6$ & 35 & $84.9 \pm 6.8$ & $5.0 \times 10^{4}$ & $1.3 \times 10^{5}$ & 2.66 \\
& & & & & & \\
sMMA20 & $59.6 \pm 2.3$ & 45 & $87.7 \pm 2.2$ & $5.1 \times 10^{4}$ & $1.2 \times 10^{5}$ & 2.42 \\
\hline MMA200 & $67.3 \pm 12.3$ & 20 & $74.8 \pm 5.8$ & $8.0 \times 10^{4}$ & $2.2 \times 10^{5}$ & 2.73
\end{tabular}

Irgacure ${ }^{\circledR} 184+\operatorname{Irgacure}{ }^{\circledR} 819 \quad d$ MMA40 $\quad 51.9 \pm 2.9 \quad 25 \quad 60.3 \pm 8.1 \quad 6.0 \times 10^{4} \quad 3.4 \times 10^{5} \quad 2.70$

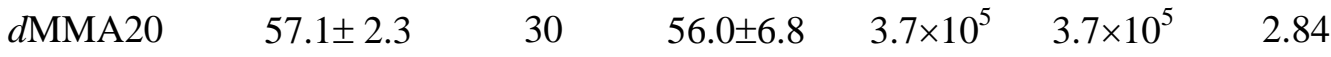


Table 3 Conversion and molecular weight of decellularized-dermis/PMMA complexes.

\begin{tabular}{ccccc}
\hline & $\begin{array}{c}\text { Conversion } \\
(\%)\end{array}$ & $\begin{array}{c}M_{\mathrm{n}} \\
(\mathrm{g} / \mathrm{mol})\end{array}$ & $\begin{array}{c}M_{\mathrm{w}} \\
(\mathrm{g} / \mathrm{mol})\end{array}$ & $M_{\mathrm{w}} / M_{\mathrm{n}}$ \\
\hline $\begin{array}{c}\text { Decellularized } \\
\text { dermis/sPMMA200 } \\
\text { complex }\end{array}$ & $54.6 \pm 4.4$ & $7.5 \times 10^{4}$ & $2.6 \times 10^{5}$ & 3.47 \\
$\begin{array}{c}\text { Decellularized } \\
\text { dermis/dPMMA200 } \\
\text { complex }\end{array}$ & $82.6 \pm 5.1$ & $7.3 \times 10^{4}$ & $2.6 \times 10^{5}$ & 3.55 \\
\hline
\end{tabular}



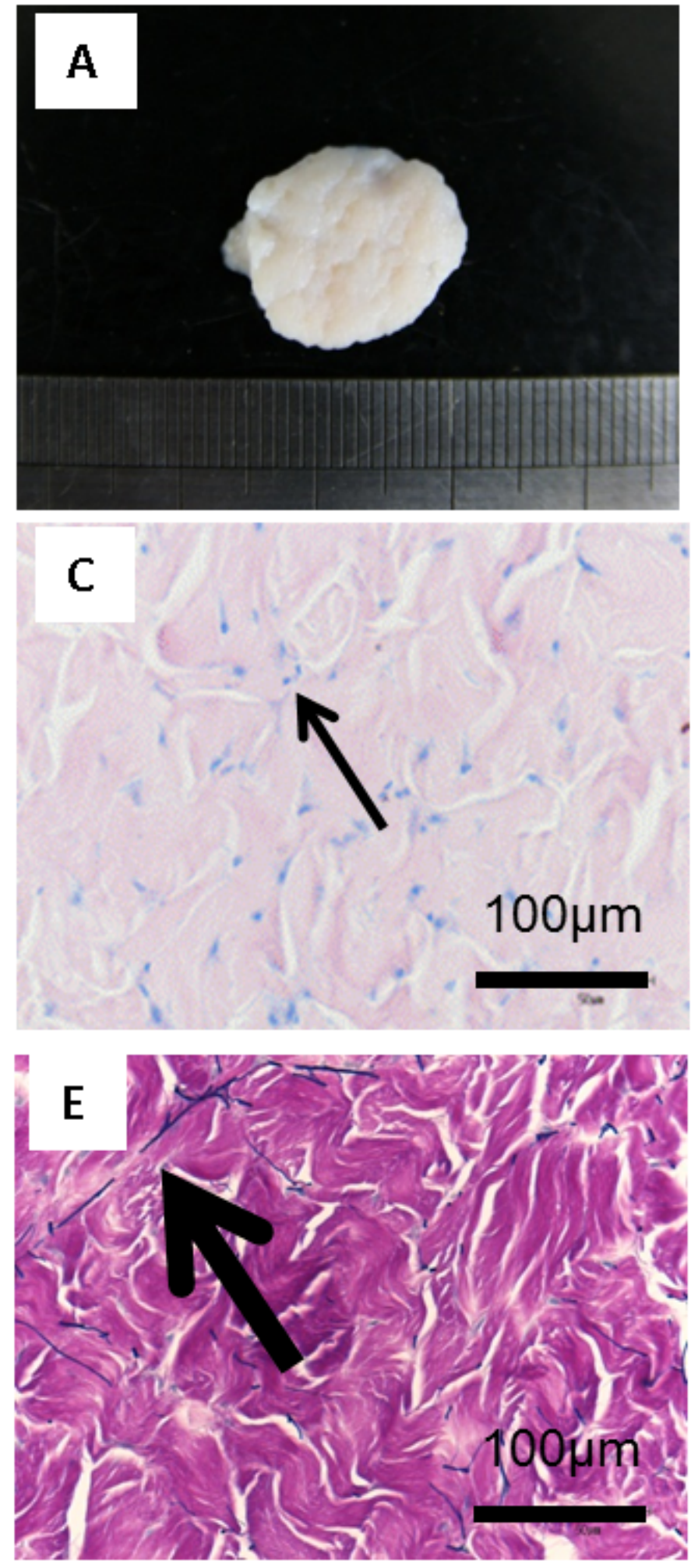
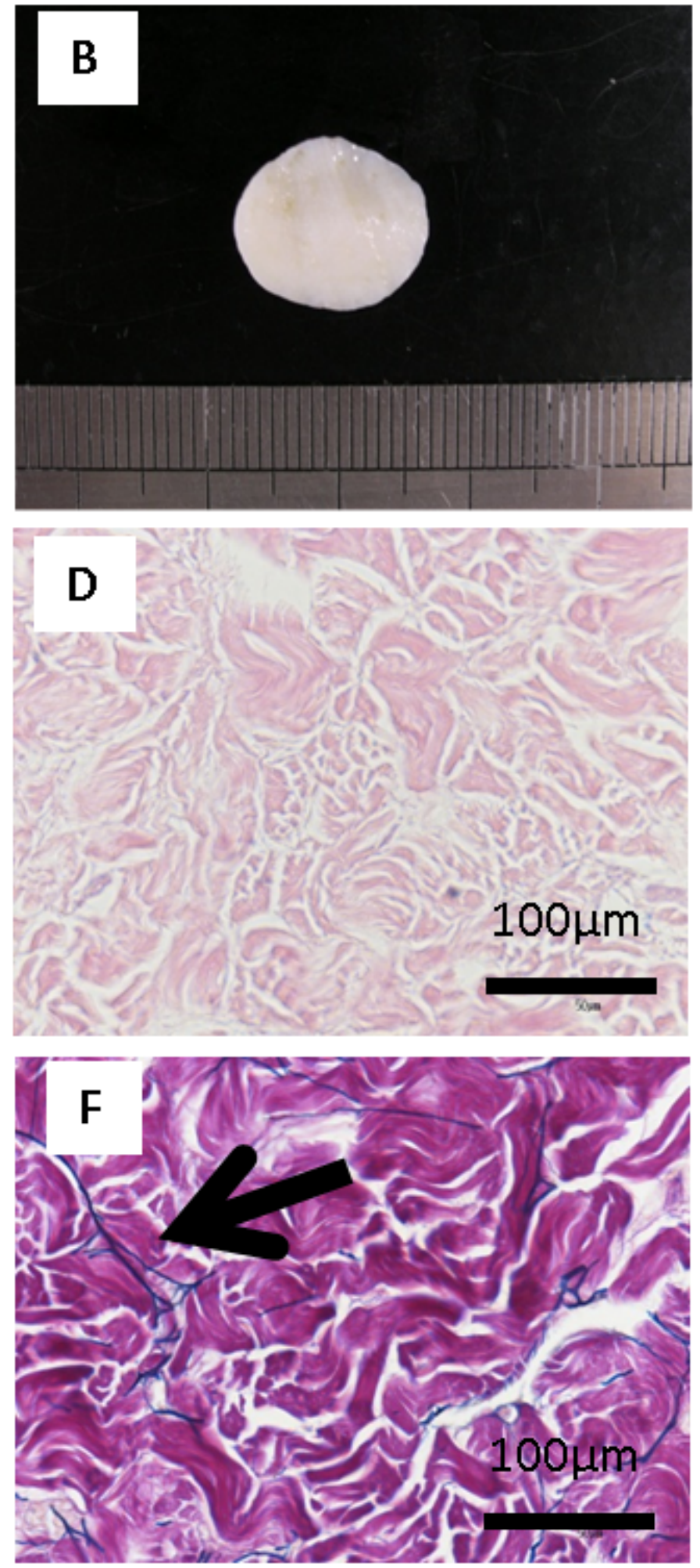
Figureโ2
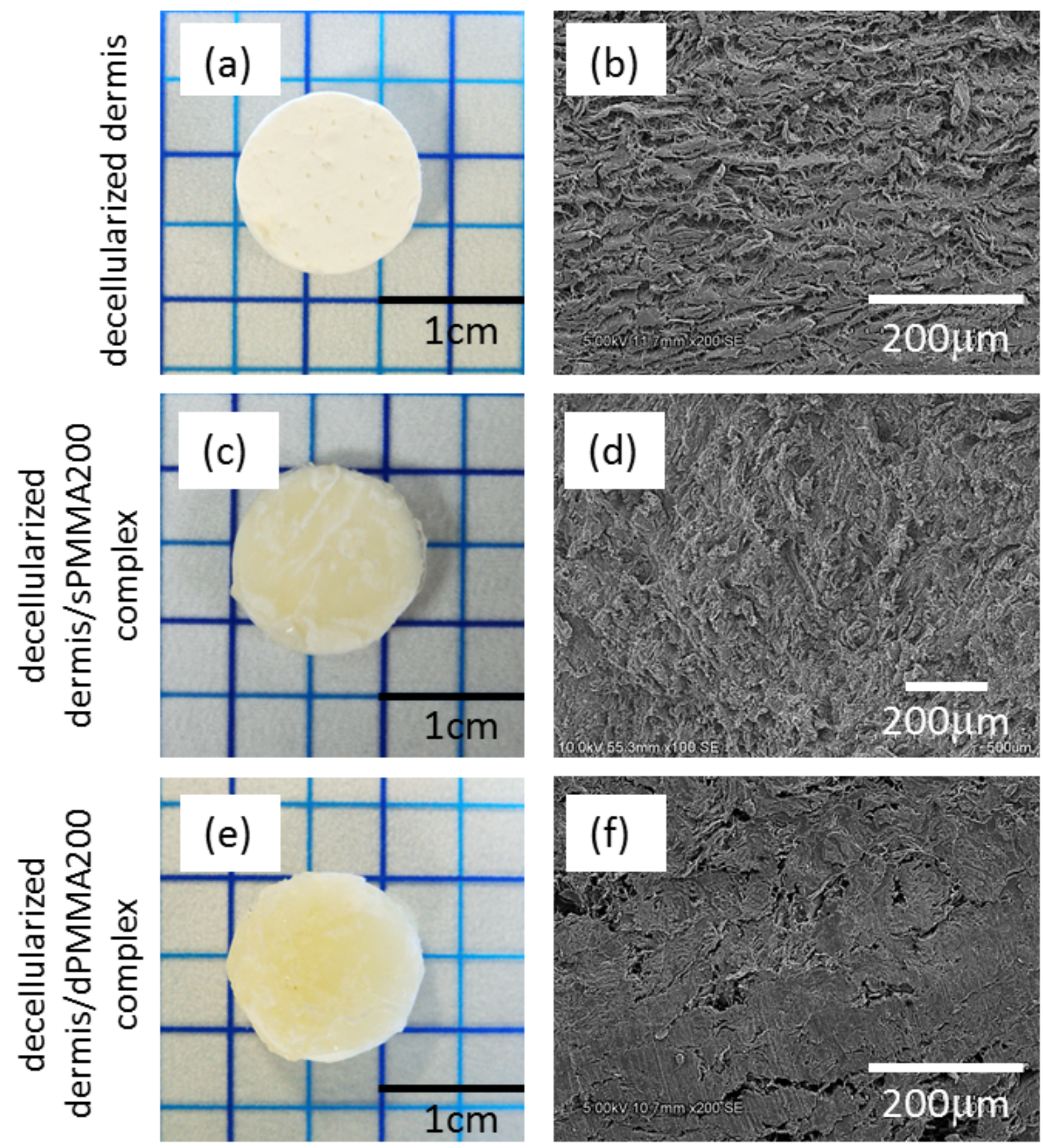
Figure $\llbracket 3$
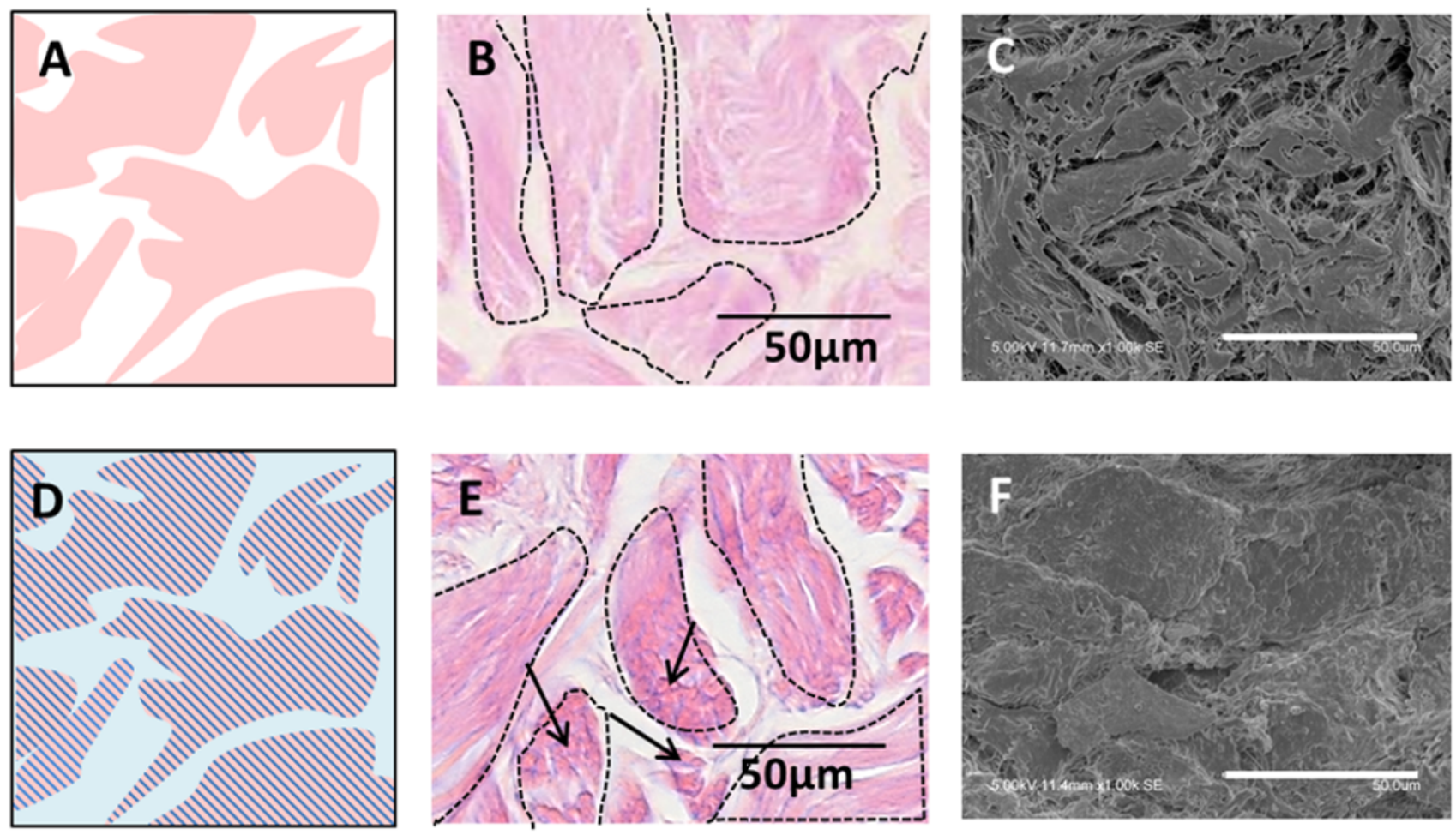
Figure $\llbracket 4 \square$

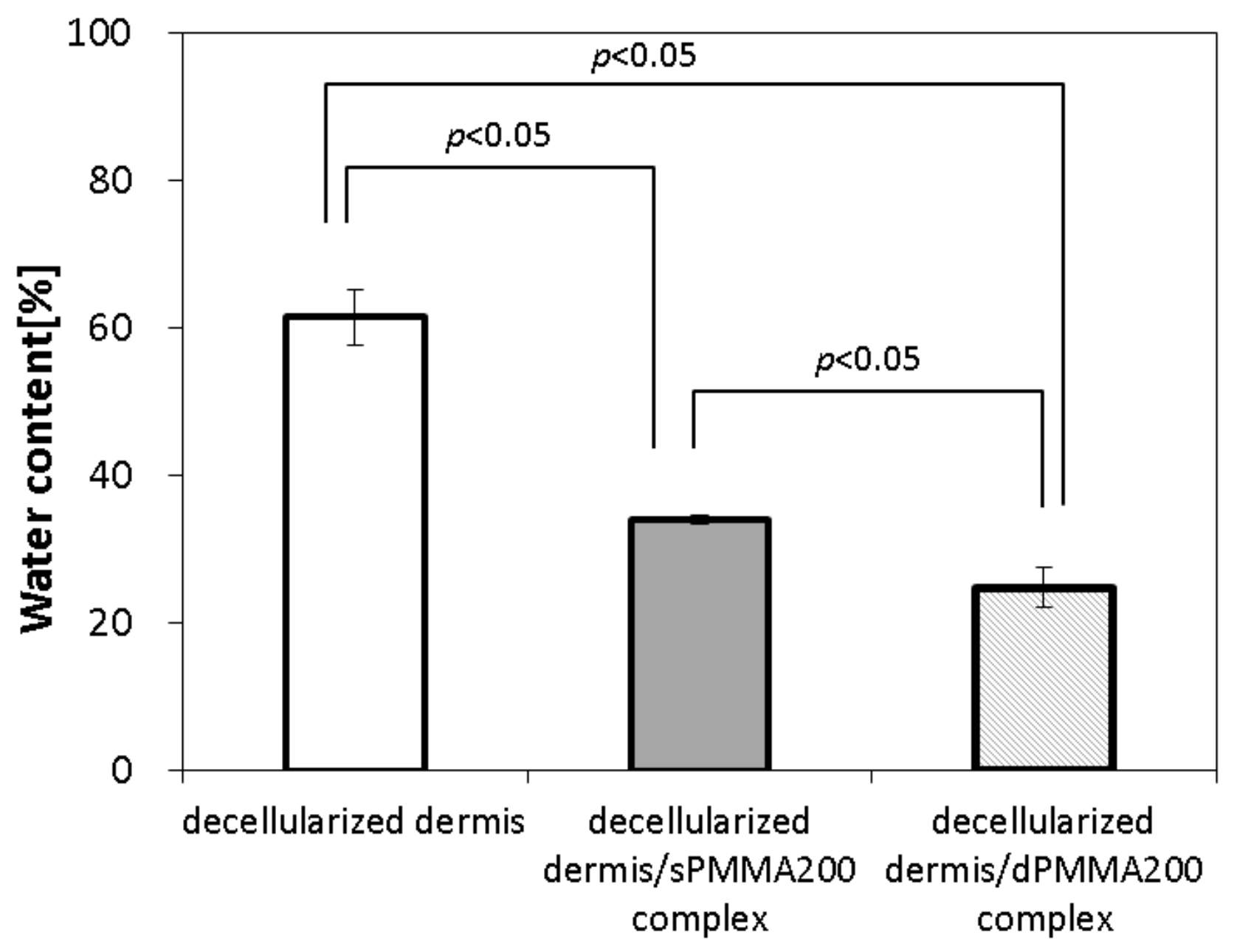




\section{Figure $\llbracket 5$}
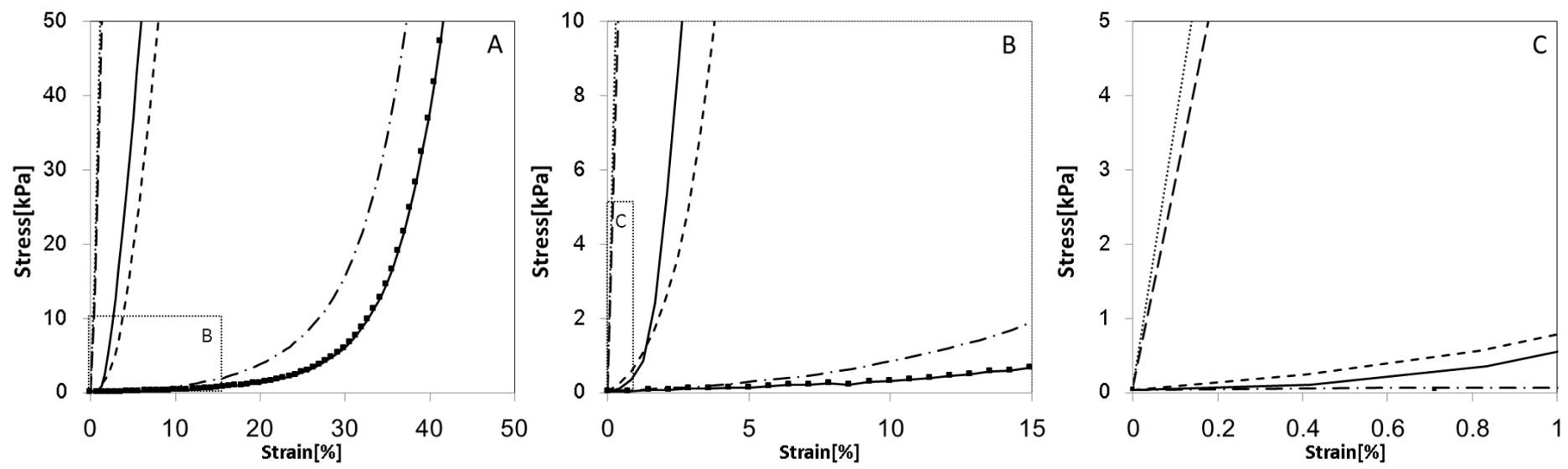
Figure 6

A

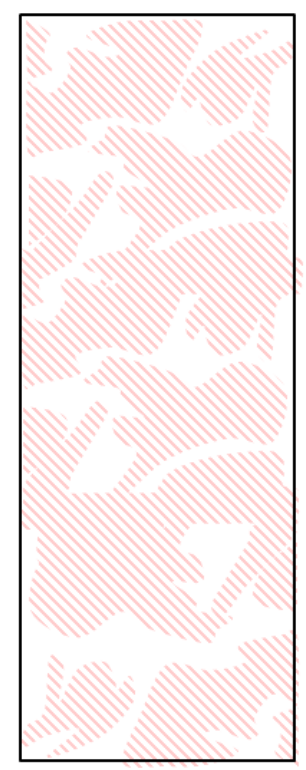

Dermis

B

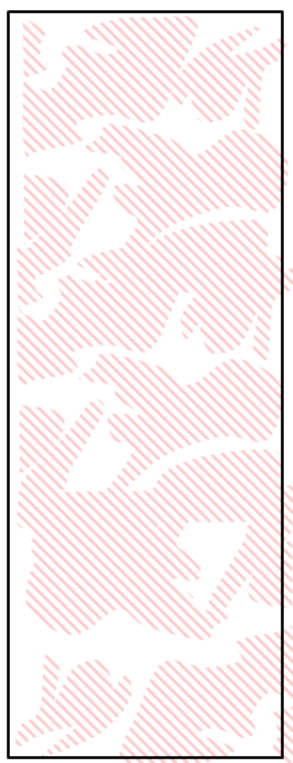

Dermis
Monomer Irgacure184

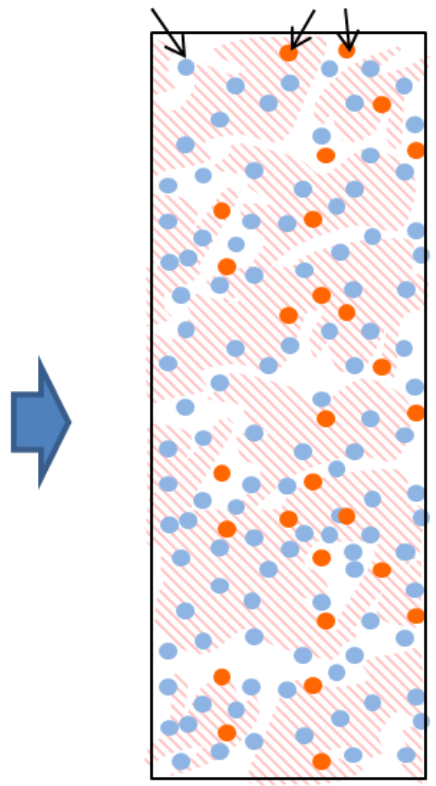

monomer+|ragacure184

Irgacure819

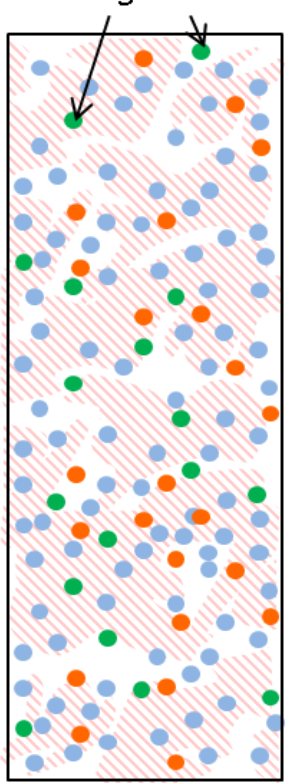

monomert

Iragacure184/Iragacure819
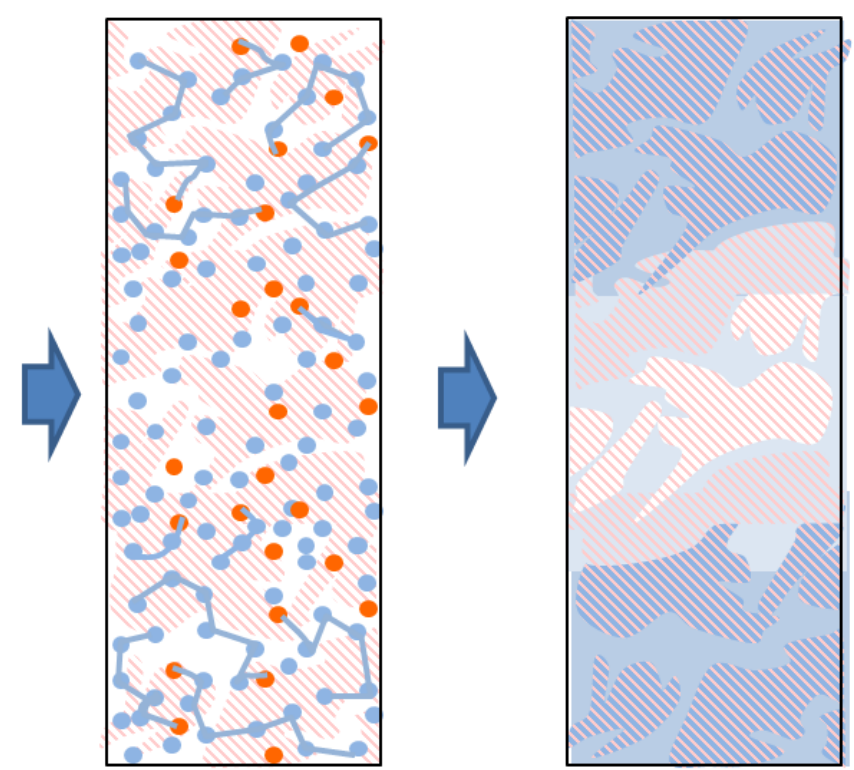

UV photopolymerization

Decellaulrized dermis/sPMMA200 complex
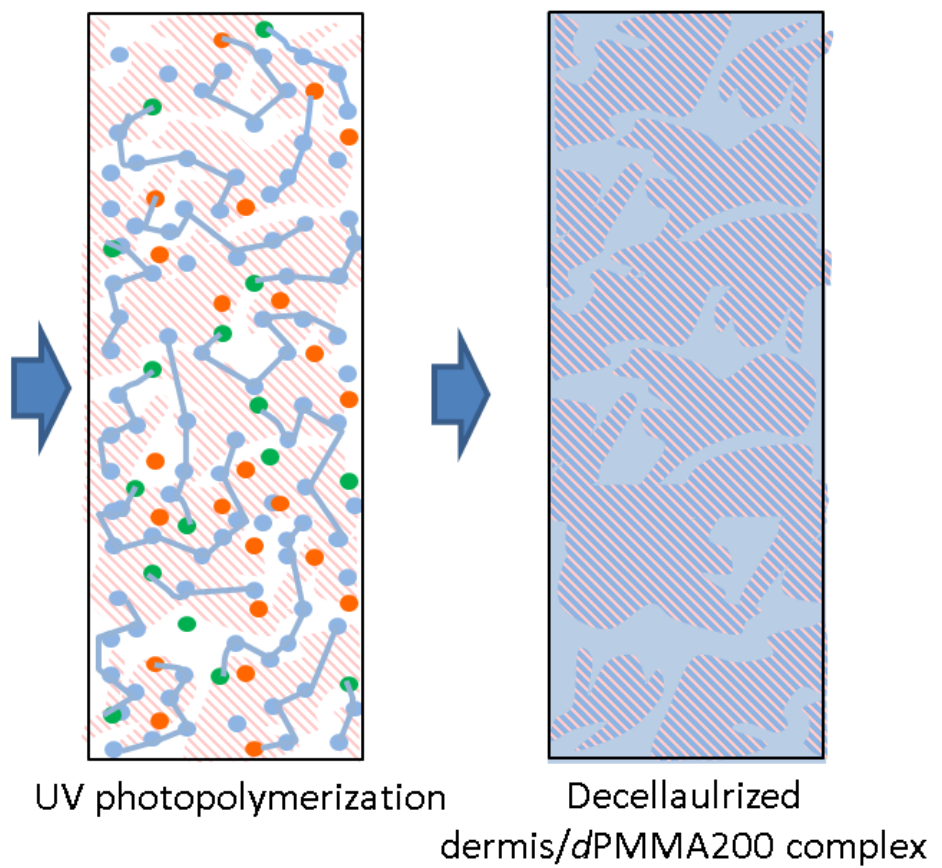

Decellaulrized

UV photopolymerization 
Collagen
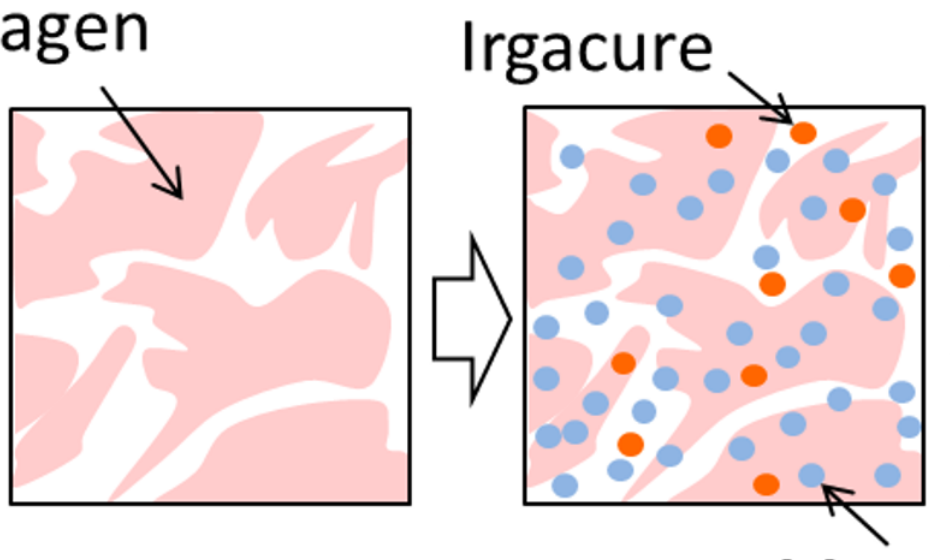

Irgacure

Monomer

Dermis
Polymer

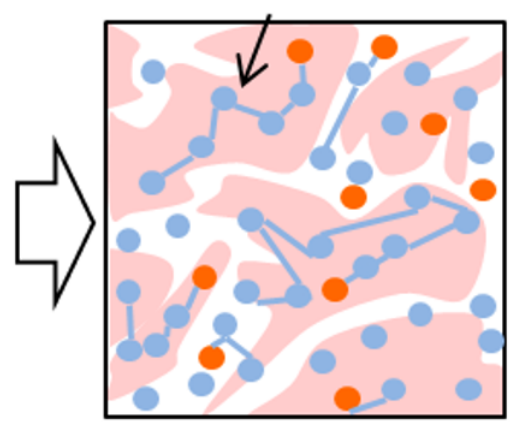

Dermis/monomer+Iragacure
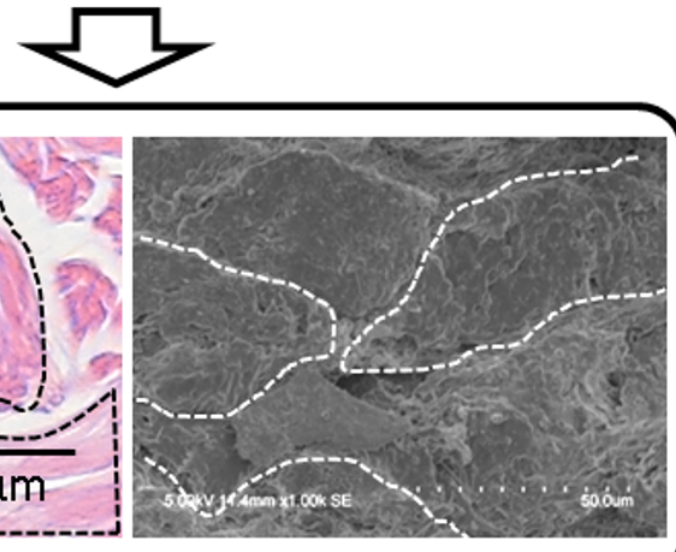

\section{Complex}

